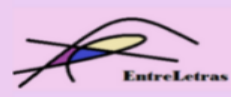

REVISTA ENTRELETRAS (ARAGUAÍNA), V. 12, N. 3, SET./DEZ. 2021 (ISSN 2179-3948 - ONLINE)

\title{
MAR PARAGUAYO: \\ O EXPERIMENTALISMO LINGUÍSTICO NAS FRONTEIRAS DA DESCOLONIZAÇÃO
}

\section{MAR PARAGUAYO: \\ LINGUISTIC EXPERIMENTALISM AT THE FRONTIERS OF DECOLONIZATION}

DOI 10.20873/uft2179-3948.2021v12n3p210-223

\section{Nádia Nelziza Lovera de Florentino ${ }^{1}$}

Resumo: Estruturado a partir de um relato híbrido que se estabelece nas fronteiras entre os gêneros, entre as línguas e entre as culturas, Mar paraguayo (1992) se constitui como um romance ímpar, capaz de instigar reflexões de diversas naturezas. Nessa perspectiva, este trabalho se propõe a articular o hibridismo, a devoração cultural antropofágica observadas no romance a um movimento em direção à descolonização, à libertação das imposições do colonialismo e do neocolonialismo e das estruturas discursivas do poder. São utilizadas as conceituações de Santiago (2000) e Mignolo (2003), além de outros teóricos dos estudos literários e culturais para, em um primeiro momento, demonstrar o trânsito entre as fronteiras presentes desde o título do romance e, posteriormente, relacionar esse trânsito a uma via de descolonização e bilinguajamento. Por fim, o trabalho evidencia o labor artístico com a linguagem presente no romance e que revela a representação do ser fronteiriço e seu discurso sem fronteiras que questiona a tradição e as gramáticas, o colonialismo e o neocolonialismo.

Palavras-chave: Mar paraguayo; experimentalismo linguístico; descolonização.

Abstract : Structured from a hybrid story that establishes itself on the borders between genres, between languages and between cultures, Mar paraguayo (1992) is constituted as a unique novel, capable of instigating reflections of different natures. From this perspective, this work proposes to articulate the hybridity, the anthropophagic cultural devotion observed in the novel, to a movement towards decolonization and liberation from the impositions of colonialism and neocolonialism and from the discursive structures of power. Conceptions of Santiago (2000) and Mignolo (2003) are used, in addition to other theorists of literary and cultural studies to initially demonstrate the transit between the borders present since the title of the novel and later relate this transit to a route of decolonization and bilingualization. Finally, the work highlights the artistic work with the language present in the novel and which reveals the representation of the border being and its borderless discourse that questions tradition and grammars, colonialism and neocolonialism.

Keywords: Mar paraguayo; linguistic experimentalism; decolonization.

\footnotetext{
1 Mestre em Estudos Literários pela UFMS, doutora em Letras pela UNESP, docente do Departamento de Línguas Estrangeiras e do Mestrado Acadêmico em Letras da Universidade Federal de Rondônia - UNIR. Membro do Grupo de Estudos Linguísticos, Literários e Socioculturais - GELLSO (CNPq). E-mail: nadianelziza@unir.br ORCID: https://orcid.org/0000-0002-7088-373X
} 


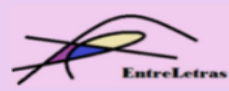

REVISTA ENTRELETRAS (ARAGUAÍNA), V. 12, N. 3, SET./DEZ. 2021 (ISSN 2179-3948 - ONLINE)

\section{Introdução}

Quatro anos antes de ser publicado pela Editora Iluminuras em parceria com a Secretaria de Estado da Cultura do Paraná, um trecho de Mar paraguayo apareceu no lendário suplemento literário Nicolau. Nessa primeira aparição, que consiste na parte que, posteriormente, seria denominada de "Ñe'ẽ" - termo utilizado para referir palavra ou conversa em guarani - Wilson Bueno esclarece que se trata de uma novela em progresso em que "[...] surge uma terceira 'língua' situada num vértice textual onde as gramáticas perdem a linha dura e cedem à voragem - vórtice duplo [...]" (BUENO, 1987, p. 25).

Ainda antes de sua publicação oficial, o romance de Wilson Bueno já se delineia como uma aposta no experimentalismo linguístico e na ausência de fronteiras, que marcariam todo o legado literário de Wilson Bueno. Se no trecho inicial já pode ser visualizada a mescla de português e espanhol, é somente na versão publicada em livro que aparecem as palavras em guarani, que se destacam em meio às memórias e confidências da "marafona del balneário", que transita entre as culturas, entre as fronteiras, entre as línguas e entre os gêneros, nas mais variadas acepções do termo.

Nessa perspectiva, diante do hibridismo, da devoração cultural e antropofágica que se configuram no relato híbrido da protagonista narradora, este trabalho se propõe a realizar uma leitura de Mar paraguayo (1992) a partir da apresentação do experimentalismo linguístico e a utilização do guarani como uma via de descolonização, na medida em que realiza um movimento oposto ao perpetuado pelo discurso colonial e neocolonial de unidade e pureza, conforme apontado por Santiago (2000), reagindo também às estruturas discursivas de poder, como no delineamento do "bilinguajamento" proposto por Mignolo (2003).

Como forma de demonstrar como o romance se estrutura a partir da confluência de fronteiras e línguas, a primeira parte do trabalho se dedica a demonstrar como o livro transita pelas Américas a partir de suas publicações em quatro países e da tentativa de tradução pela canadense Erin Moure. Ainda nessa parte, há a explicitação da metáfora do mar paraguayo e como ela aponta para a ausência de fronteiras sobre a qual o romance se assenta.

Na segunda parte, o trabalho se ocupa da explicitação a respeito da utilização da linguagem como um caminho para a descolonização, na resistência aos discursos apregoados pelo colonialismo e neocolonialismo. Para tanto, parte-se da análise do relato híbrido da protagonista narradora e de sua relação com outras obras da literatura brasileira, a fim de 


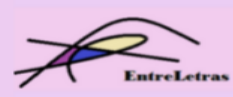

REVISTA ENTRELETRAS (ARAGUAÍNA), V. 12, N. 3, SET./DEZ. 2021 (ISSN 2179-3948 - ONLINE)

demonstrar como ele desloca as línguas hegemônicas para projetar a língua indígena em um movimento de descolonização e de bilinguajamento.

Por fim, o trabalho aponta para as particularidades estéticas evidenciadas no trabalho com a linguagem capaz de levar a inúmeras leituras, das quais a resistência ao colonialismo e ao neocolonialismo é apenas uma delas. Quase trinta anos após sua primeira publicação e trinta e quatro anos após sua primeira aparição, Mar paraguayo (1992) continua a ser referência de leitura e de reflexão sobre o sujeito fronteiriço que se equilibra pelas fronteiras através da linguagem.

\section{Mar paraguayo: o trânsito pelas fronteiras e pelas línguas}

Mar paraguayo (1992) é um dos romances mais conhecidos de Wilson Bueno e, talvez, o mais aclamado pela crítica. Com as memórias e confidências da "marafona del balneário", o autor paranaense se consagra como o escritor do intraduzível e, ao mesmo tempo, abre as portas para uma nova forma de linguagem literária que anos mais tarde seria denominada de portunhol selvagem, consagrando poetas como Douglas Diegues, Fabián Severo, dentre outros (FLORENTINO, 2016).

O romance foi publicado pela primeira vez em 1992. Posteriormente, foi editado no Chile em 2001, na Argentina, em 2005 e no México, em 2006. Assim, através de suas quatro edições, o livro circula do sul até o norte da América Latina, demonstrando um trânsito pelas fronteiras geográficas e uma presença marcante tanto no contexto literário brasileiro como também nos países de língua espanhola. Nas edições voltadas aos hispanofalantes, apenas o prefácio e o elucidário foram traduzidos, o texto permanece o mesmo. Para os leitores da América do Norte, há a tentativa de tradução de Erin Moure utilizando as três línguas mais comuns da cidade de Montreal, no Canadá. Assim, no projeto de tradução de Mar paraguayo são utilizadas a língua “Kanien'kehá':ka” e uma mescla de inglês e francês.

Desse modo, nesse romance, pode ser observada uma clara travessia entre as fronteiras linguísticas, geográficas e culturais e também entre os gêneros, em todas as acepções possíveis do termo. No que se refere ao gênero, o discurso da protagonista narradora transita entre a poesia e a prosa, em uma confluência entre os gêneros literários, e também 


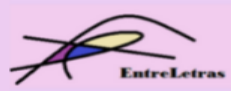

REVISTA ENTRELETRAS (ARAGUAÍNA), V. 12, N. 3, SET./DEZ. 2021 (ISSN 2179-3948 - ONLINE)

entre o masculino e o feminino, borrando e apagando as fronteiras entre os gêneros e as categorizações sexuais ${ }^{2}$.

Por sua vez, o trânsito pelas fronteiras linguísticas, geográficas e culturais se inicia logo no título do livro, composto de duas palavras: o substantivo mar e o gentílico paraguayo cuja combinação apresenta a designação de um espaço geográfico inexistente, uma vez que o Paraguai não possui saída para o mar. Assim, se não existe um mar paraguaio na configuração espacial da América do Sul, o que representaria o título do romance?

Em uma primeira tentativa de resposta a essa pergunta, há que se considerar que o espaço no qual se desenvolve a narrativa em Mar paraguayo (1992) é a praia de Guaratuba, localizada no litoral paranaense, no Brasil. Ao iniciar propriamente o seu relato, na parte "Ñe'ê", a protagonista esclarece: "Yo soy la marafona del balneário. A cá, en Guaratuba, vivo de suerte" (BUENO, 1992, p. 15). Ela se reconhece como uma marafona ${ }^{3}$ que vive como sortista e apresenta como espaço físico a cidade de Guaratuba. Em outro trecho do romance, a narradora se apresenta a partir da dualidade bruxa/guru que provoca, ao mesmo tempo, temor e admiração nos moradores da cidade: “[...] el temor ô mismo la admiración que provoco en los nativos deste pedaço de mar en Guaratuba del Paraná, a cada vez que saigo - bruja ô guru” (BUENO, 1992, p. 59). Nesse trecho, aparece mais uma vez o nome Guaratuba grafado com letra maiúscula acompanhado do pronome possessivo espanhol del e do termo Paraná, também grafado em letra maiúscula.

O mar geográfico apresentado no romance é aquele localizado na cidade de Guaratuba. Popularmente, a praia de Guaratuba é conhecida como "praia dos paraguaios" e, assim, o espaço no qual se desenvolve a narrativa representa um mar que pode ser considerado " [...] geograficamente como brasileiro e paraguaio por influência - haja vista que as praias de Guaratuba são assiduamente frequentadas por turistas provenientes do país vizinho" (FLORENTINO, 2011, p. 19). Além disso, se a questão do mar paraguaio for levada ao patamar histórico, poderiam ser elencados ao espaço no qual o romance se desenvolve tanto

2 Uma análise detalhada a respeito do trânsito entre gêneros em Mar paraguayo que resulta na delineação do (trans) gênero pode ser vislumbrada no artigo "Wilson Bueno e o (trans)gênero: uma leitura de Mar Paraguayo e Jardim Zoológico”, publicado por FLORENTINO e ESTEVES em 2019.

3 O termo marafona, de origem árabe, refere-se a um tipo de boneca sem rosto e também pode designar meretriz (FLORENTINO, 2016) 


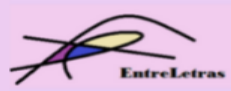

REVISTA ENTRELETRAS (ARAGUAÍNA), V. 12, N. 3, SET./DEZ. 2021 (ISSN 2179-3948 - ONLINE)

as motivações por trás da Guerra do Paraguai quanto o exílio do ditador paraguaio Alfredo Stroessner, conforme aponta Wilson Bueno em entrevista.

Ao lado desse mar geográfico, encontra-se, no romance, um mar que ultrapassa as fronteiras espaciais e que se estabelece no entre-línguas e nos entre-lugares. Um dos indícios dessa travessia pode ser observado na composição do título do romance, no qual a ideia de mar encontra-se expressa, pelo menos, três vezes e em três línguas: em mar, que pode ser lido tanto em português quanto em espanhol, e em paraguayo, derivada de Paraguay, palavra em guarani composta da justaposição dos termos para - mar -, gua - origem ou morador - e y, que pode significar tanto água quanto uma grande extensão de água, rio ou mar (GUASH \& ORTIZ, 1996).

Se as três referências ao mar constantes no título não fazem sentido geograficamente, o mar pode ser entendido como uma metáfora que pode se relacionar tanto à dimensão ontológica do ser, expresso nas confidências e lembranças de um ser híbrido em constante conflito, quanto à ausência de fronteiras. Ao comentar sobre a questão do mar em Mar paraguayo (1992), Wilson Bueno afirma: “[...] ao juntar as 'geografias' e dotar o Paraguai país mediterrâneo - de um mar, eu o fiz como quem embaralha todas as fronteiras. Daí a mistura e a inversão nesse livro, além de sua inerente 'perversão"” (BUENO, s.d.).

Assim, a inconsistência geográfica do título do romance antecipa a configuração de um espaço movediço e, assim como todas as águas convergem para o mar, nesse mar paraguayo, todas as fronteiras, todas as línguas e todas as culturas confluem. O mar representa, então, o próprio relato, híbrido e constituído a partir da mescla de português, espanhol, guarani e outros idiomas, como o francês, o italiano e o inglês. Na confluência de idiomas, o guarani assume uma posição fundamental em toda a narrativa, conforme expresso no aviso em forma de notícia que abre o relato da marafona:

\footnotetext{
Un aviso: el guarani es tan essencial en nesto relato quanto el vuelo del párraro, lo cisco en la ventana, los arrulhos del português ô los derramados nerudas en cascatas num solo só suicídio de palabras anchas. Una el error dela outra. Queriendo-me talvez acabe aspirando, en neste zoo de signos, a la urdidura essencial del afecto que se vá en la cola del escorpión [...]. (BUENO, 1992, p. 13).
}

Nesse trecho, é possível constatar que a língua indígena é apresentada como um elemento essencial em meio ao "suicídio" das demais palavras. Enquanto as outras línguas se 


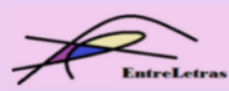

REVISTA ENTRELETRAS (ARAGUAÍNA), V. 12, N. 3, SET./DEZ. 2021 (ISSN 2179-3948 - ONLINE)

constituem "una el error dela outra", o guarani permanece como língua que merece atenção. Nas palavras de Wilson Bueno:

\begin{abstract}
Em todo o transcurso do Mar..., o guarani se impõe, exilado, feito resistência, palavras-poema, brilho e rebrilho, salpicos de luz. Contudo, o guarani não se mistura, se recusando a participar desse jogo floral entre o português e o espanhol, a engendrar portunhólicas selvagerias. O guarani é um elemento autóctone no possível "panaroma" de Mar Paraguayo (BUENO, 2009).
\end{abstract}

Em uma análise das palavras que compõem o romance, observa-se que a afirmação de Wilson Bueno se comprova na medida em que é possível encontrar algumas formas através das quais português e espanhol se misturam no romance, como no caso da junção de palavras nas duas línguas, em “debujan” (BUENO, 1992, p. 52), “esquierda” (BUENO, 1992, p. 21), dentre outras; aparecem também termos que se constituem na transposição da pronúncia de palavras do espanhol para o português e vice-e-versa, como em "párraro" (BUENO, 1992, p. 13) e “camiños" (BUENO, 1992, p. 51). Nesse jogo entre português e espanhol, não se observa nenhuma mescla envolvendo o guarani. A língua indígena permanece sempre intacta, como em "añaretã”, "porã”, “taĩhu” (BUENO, 1992, p. 29), inferno, bonito, formiga, respectivamente.

A partir dessa constatação, pode-se elencar o guarani como um elemento fundamental na compreensão do relato da "marafona del balneário", pois aponta para um ponto de destaque em meio ao desequilíbrio e confusão, podendo remeter para a ancestralidade e para um componente pré-colonial. Segundo Bueno, “[...] parece espantoso que a língua guarani, presente no Mar..., tenha sobrevivido a séculos de dominação, subjugada através dos mais infames métodos, e que esteja aí, tensa, intensa, viva, docemente manejável pela poesia, ela própria poema em estado bruto [...]" (BUENO, 2009).

Nessa perspectiva, o mar representa o relato híbrido no qual o guarani permanece incólume, como matéria-prima para poesia, enquanto a estruturação do romance ao lado do experimentalismo linguístico apontam para a resistência contra a colonização, uma necessidade e uma luta pela libertação das imposições da colonialidade.

\title{
Mar paraguayo: A linguagem como forma de descolonização
}




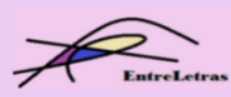

REVISTA ENTRELETRAS (ARAGUAÍNA), V. 12, N. 3, SET./DEZ. 2021 (ISSN 2179-3948 - ONLINE)

Para Silviano Santiago (2000), no texto O entre-lugar no discurso latinoamericano, no processo de colonização das Américas, além da violência, a imposição do código linguístico europeu, bem como da religião, foram fundamentais no processo de subjugação dos povos indígenas. Uma das formas de impor, ao mesmo tempo, a língua portuguesa e a fé católica era por meio da arte:

Colocar junto não só a representação religiosa como a língua européia: tal foi o trabalho a que se dedicaram os jesuítas e os conquistadores a partir da segunda metade do século XVI no Brasil. As representações teatrais, feitas no interior das tabas indígenas, comportam a mise-en-scène de um episódio de Flos Sanctorum e um diálogo escrito metade em português e a outra metade em tupi-guarani, ou, de maneira mais precisa, o texto em português e sua tradução em tupi-guarani. (SANTIAGO, 2000, p. 13).

Nas representações teatrais, era importante mesclar as línguas como forma de familiarizar os indígenas àquilo que estava sendo representado, ao mesmo tempo em que assimilavam a língua europeia a ponto de perderem, aos poucos, sua própria língua. Aos poucos, o tupi-guarani, o guarani e outras línguas indígenas foram sendo subjugadas no processo de colonização enquanto o português e o espanhol se impunham cada vez mais:

[...] A doutrina religiosa e a língua europeia contaminam o pensamento selvagem, apresentam no palco o corpo humano perfurado por flechas, corpo em tudo semelhante a outros corpos que, pela causa religiosa, encontravam morte paralela. Pouco a pouco, as representações teatrais propõem uma substituição definitiva e inexorável: de agora em diante, na terra descoberta, o código linguístico e o código religioso se encontram intimamente ligados, graças à intransigência, à astúcia e à força dos brancos. Pela mesma moeda, os índios perdem sua língua e seu sistema do sagrado e recebem em troca o substituto europeu. (SANTIAGO, 2000, p. 14).

Em Mar paraguayo (1992), esse processo se inverte. Espanhol e português aparecem subjugados em uma "mescla aberrante" (PERLONGHER, 1992, p. 9) enquanto o guarani aparece como elemento de destaque. Se na colonização a língua indígena era posta como selvagem, rude, no relato da marafona, o castelhano é visto como rude e áspero, enquanto que o guarani é a língua da emoção. No trecho "[...] Yerobi. Es la dança en el abismo dos vocacionados a lo equilibrismo - me decia, hace mucho, en rude castelhano, mi abuelita argentina, cobrando-me el gusto amargo de la derrota [...]” (BUENO, 1992, p. 21), a 


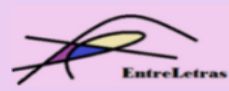

REVISTA ENTRELETRAS (ARAGUAÍNA), V. 12, N. 3, SET./DEZ. 2021 (ISSN 2179-3948 - ONLINE)

"abuelita" argentina ecoa na memória com a rudeza de sua língua, ao passo que o guarani "[...] es inofensivo e me garfo com ele toda mordida de tahiis, tahiiguaicurú, sílfides, aracutí, aririi, pucú” (BUENO, 1992, p. 34). O guarani aparece ainda como uma língua em que as palavras são mais naturais e melódicas: “[...] En mi idioma nativo las cosas san más cortas y se agregan con surda ferocidade. Ñemomirĩ. Ñemomirĩhá” (BUENO, 1992, p. 18).

A dualidade linguística entre o espanhol e o guarani, que se estabelece como um conflito interior da protagonista narradora, é reflexo de uma luta que existe no interior da cultura paraguaia “[...] la lucha de los factores hispânicos e indígenas prosigue en el fondo del espíritu mestizo"4(PLÁ, 1970, p. 19). A escritora Josefina Plá denomina essa convivência nem sempre harmoniosa entre as duas línguas no Paraguai de bilinguismo, presente em todos espaços sociais, religiosos e culturais do país. Mesmo diante de todas as tentativas de apagar o guarani da cultura paraguaia, a língua permaneceu, ainda que associada ao domínio rural, à inferioridade:

Por la vía general del bilinguismo seguirá sin embargo transitando aún por mucho tiempo la dualidad cultural y espirtitual del pueblo paraguayo. El guaraní comparado en la mayoría conservadora, apoyado en la lenta transformación de los estratos culturales inferiores y el predominio de la vida rural; el español, cimentado en una misma transformación y en la medida en que es vehículo de una cultura universal en inevitable penetración crecente [...] (PLÁ, 1970, p. 21) ${ }^{5}$

É através do bilinguismo que se estabelece a identidade cultural paraguaia, o que foi reforçado pela Constituição de 1992, que elevou o guarani a língua oficial. Mar paraguayo (1992) foi publicado no mesmo ano dessa oficialização e, na época em que foi escrito, certamente o guarani no Paraguai ainda estava no patamar de língua relegada a língua inferior, após os anos de repressão pela ditadura Stroessner no país.

Segundo Silviano Santiago (2000), é significativo o esforço do conquistador em evitar a todo custo o bilinguismo a fim de manter sua hegemonia, utilizando o poder da língua e o poder da Igreja para se impor cada vez mais. Assim, nas palavras do autor, "Evitar o bilinguismo significa evitar o pluralismo religioso e significa também impor o poder colonialista. Na álgebra do conquistador, a unidade é a única medida que conta. Um só Deus,

4 Tradução nossa: [...] A luta dos fatores hispânicos e indígenas prossegue no interior do espírito mestiço

5 Tradução nossa: Através da via geral do bilinguismo, a dualidade cultural e religiosa do povo paraguaio continuará, no entanto, transitando ainda por muito tempo. O guarani amparado na maioria conservadora, apoiado na lenta transformação dos estratos culturais inferiores e o predomínio da vida rural; o espanhol, cimentado nessa mesma transformação e na medida em que é veículo de uma cultura universal em uma inevitável e crescente penetração. 


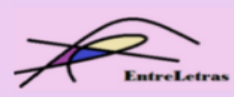

REVISTA ENTRELETRAS (ARAGUAÍNA), V. 12, N. 3, SET./DEZ. 2021 (ISSN 2179-3948 - ONLINE)

um só Rei, uma só Língua: o verdadeiro Deus, o verdadeiro Rei, a verdadeira Língua" (SANTIAGO, 2000, p. 14).

Nessa perspectiva, estabelece-se tanto no colonialismo quanto, posteriormente, no neocolonialismo o movimento em direção à imposição da unidade e da pureza como formas de dominação da Metrópole sobre a Colônia. O esforço de autores de diversas épocas em evitar apagamento das línguas indígenas através de sua utilização em textos literários representa, então, a resistência e a tentativa de romper com essa imposição de unidade e pureza.

No discurso híbrido da marafona, o uso do guarani, ao lado do experimentalismo, podem configurar-se como instrumentos que questionam justamente esse conceito de unidade, uma vez que se baseia em uma confluência de culturas e nacionalidades, como também o conceito de pureza, na medida em que mescla o português e o espanhol e destaca o guarani como elemento puro, invertendo a ideia colonizadora de pureza. Além disso, a resistência do guarani no romance pode ser relacionada a uma necessidade de deslocar as línguas coloniais, no caso o português e o espanhol, e projetar a língua ameríndia

Essa necessidade de deslocamento das línguas coloniais ou hegemônicas é denominada por Walter Mignolo (2003) de "bilinguajamento", que segundo o autor, consiste justamente no "[...] deslocamento das línguas hegemônicas e imperiais (espanhol, inglês) e sua recolocação dentro da perspectiva das línguas ameríndias [...]" (MIGNOLO, 2003, p. 366).

Diferente do Paraguai, que tem a língua guarani como um elemento fundamental e visível de sua identidade cultural, no Brasil, as línguas indígenas, apesar de terem marcado de forma profunda o português brasileiro, são cada vez menos valorizadas, desaparecendo aos poucos. Nesse cenário, a publicação de Mar paraguayo no Brasil, em plena década de 1990, quando o país estava em processo de redemocratização, com a utilização do guarani e uma espécie de portunhol como veículo de linguagem, mostra claramente esse movimento de retomar a língua ameríndia, colocando-a no centro e deslocando as línguas hegemônicas, no caso o português e o espanhol, fundindo-as e criando uma língua híbrida.

Ao retratar suas origens, a protagonista narradora coloca o elemento indígena como parte fundamental de sua constituição enquanto sujeito. O local de seu nascimento é revelado como sendo em um lugar "[...] al fondo del fondo del fondo de mi país - esta hacienda guarani, guarânia y soledad" (BUENO, 1992, p. 16). Assim, utilizando a repetição da palavra "fondo", que corresponde a "fundo" no português, a narradora reforça o fato de que sua terra 


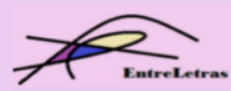

REVISTA ENTRELETRAS (ARAGUAÍNA), V. 12, N. 3, SET./DEZ. 2021 (ISSN 2179-3948 - ONLINE)

de origem se encontra no interior do Paraguai. Entendendo o interior não apenas como a distância dos grandes centros, mas também em sua relação com profundidade, pode-se relacionar a origem da marafona ao âmago da cultura paraguaia, uma vez que ela caracteriza esse local como uma "hacienda", porção de terra guarani cuja principal marca é a tradição indígena.

Historicamente, a hacienda é associada a uma propriedade em que o colonizador exerce o controle da terra e de seus habitantes, e esse tipo de propriedade era comum no contexto de colonização nas Américas. A hacienda é o oposto do conceito de comunidade dos indígenas, em que tudo é coletivo; na propriedade privada do colonizador, imperam o individual e o privado e a dominação é marcada pela opressão. Assim, ao utilizar o termo "hacienda guarani" tendo como complemento os termos "guarânia", um ritmo paraguaio lento e melancólico e "soledad", solidão, observa-se no romance esse processo de resistência à colonização e de valorização do elemento indígena.

Outra marca de identificação da protagonista com o elemento ameríndio aparece no ponto em que, ao rememorar a relação sexual com o niño, personagem de dezessete anos com quem vive um tórrido caso de amor, ela, em contraposição ao adolescente, que possui as características do europeu loiro de olhos azuis, identifica-se com uma série de termos que remetem ao indígena:

[...] clamê por el, por el niño, para que yo lo possuísse más que el a mi, todas las ondas y todo el gusto marafo del sol - sêmen y água, bodas y crepúsculo, lo abraçaria hecho asi una madre grande y imensa madona macunaíma, índia, pajé, tupã, yo e mis tan locos esplendecientes puesto que con el, lo êxtase era en ênfase represado por el gozo del mar, muñeca de trapo, trepadora, yo la marafona del balneário [...]. (BUENO, 1992, p. 66).

Com “macunaíma”, “índia”, “pajé”, “tupã”, a narradora afirma sua identidade indígena e, ao mesmo tempo, estabelece um diálogo com a cultura indígena e também com a tradição literária, em clara referência ao herói sem nenhum caráter do romance de Mário de Andrade. Ao estabelecer esse diálogo, a marafona insere-se no perfil indígena da literatura brasileira, invertendo a ordem do mito fundador, na medida em que, nos romances indianistas do romantismo, como Iracema (1865), de José de Alencar, a jovem índia é conquistada pelo viajante europeu, enquanto em Mar paraguayo (1992), o niño, como jovem europeu, é conquistado e até mesmo devorado pela índia já madura. Já em relação às correspondências com Macunaíma (1928), com o uso do portunhol e do guarani, o romance se configura a 


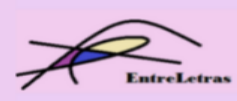

REVISTA ENTRELETRAS (ARAGUAÍNA), V. 12, N. 3, SET./DEZ. 2021 (ISSN 2179-3948 - ONLINE)

partir de um canibalismo linguístico, remetendo tanto ao Manifesto Antropófago (1928) quanto às obras de Mário de Andrade e aos modernistas.

Assim como na narrativa do herói sem nenhum caráter, o relato da marafona se propõe a uma busca pela originalidade, em uma ruptura com a tradição, levando a mitologia indígena ao extremo mediante o experimentalismo linguístico, fundindo elementos da cultura ocidental ao ponto de obter o hibridismo baseado na antropofagia. Um exemplo disso pode ser visualizado no ponto em que a narradora se senta para tecer sua renda ñanduti rememorando suas lembranças, emoções e sentimentos:

la fala ancestral de padres y avuêlos que se van de infinito a la memoria, se entretienem todo habla y tricô: estas vozes guaranis solo se enterniecen se todavia tecen: ñandú: no hay mejor tela de que la telaraña de las urdidas hojas: higuêra: sombrêro: de sus urdidas hojas de pleno acordo, ñandu, de acordo y de entremeio por los arabescos que, sinfonia, se entrelaza, radrez de verde e ave y canto, en el andamento feliz de una libertad: ñanduti: ñandurenimbó (BUENO, 1992, p. 42-43).

As vozes guaranis vão sendo tecidas na urdidura do relato e o resultado é o ñadurenimbó, teia de aranha. Para tecer sua teia, seu ñanduti, um tipo de renda famosa no Paraguai, a narradora utiliza o tricô e o crochê, confecções tradicionalmente europeias. Assim, o material é guarani, ancestral, o instrumento é europeu e o resultado é uma trama híbrida, que se constitui na fusão e assimilação de culturas.

Nessa perspectiva, o elemento indígena ao lado do experimentalismo com o português e o espanhol no romance fazem com que ele se insira no movimento de ruptura da opressão pelo discurso propagada tanto pelo colonialismo quanto pelo neocolonialismo e também como uma forma de "bilinguajamento", que segundo Mignolo (2003), processa-se em um momento anterior à linguagem:

\footnotetext{
Para fazê-lo, é necessário pensar o linguajamento além das línguas: o momento "anterior" à linguagem (não, evidentemente, numa história da língua desde o paleolítico até o presente, mas nas práticas linguísticas do cotidiano), quando a alienação discursiva daquilo que (na língua) chamamos de "consciência" ainda não foi articulada na estrutura discursiva do poder (MIGNOLO, 2003, p. 366).
}

Logo na parte de abertura de seu relato, a protagonista de Mar paraguayo

localiza seu relato em um local semelhante àquele proposto por Mignolo (2003) para pensar o linguajamento: ela deseja alcançar "[...] todo que vibre e tine abaixo, mucho abaixo de la linea del silêncio. No hay idiomas aí. Solo la vertigen de la linguagem. Deja-me que exista”. 


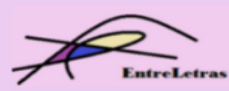

REVISTA ENTRELETRAS (ARAGUAÍNA), V. 12, N. 3, SET./DEZ. 2021 (ISSN 2179-3948 - ONLINE)

(BUENO, 1992, p. 13). Pode-se considerar, então, que o objetivo da marafona é localizar seu relato em um local livre dessa "estrutura discursiva do poder", um local onde não há idiomas, somente a vertigem da linguagem. Em uma linguagem vertiginosa, prevalecem a alucinação e a confusão, e nesse caso, fantasia e realidade se apresentam de forma embaralhada.

Segundo Adrian Cangi (2005) no texto "Imprevistos de la vida, torciones del linguaje", a vertigem produzida pela linguagem em Mar paraguayo (1992) se caracteriza como um entre-lugar:

[...] El entrelugar no se dice por zonas semánticas estables, substantivos o verbos, sino por expresiones preposicionales que afirman la tendencia elástica de los sólidos [...]. Define el umbral del entrelugar en toda su consistencia paradójica como un adentrofuera y como un tránsito. Espacio donde la intensidade produce un vértigo entre lenguas, con la fuerza de un paisaje proprio y costumbres ancestrales que se fusionan en un translinguismo migrante. (CANGI, 2005, p. 83-8431) ${ }^{6}$.

O entre-lugar que se estabelece no discurso da marafona corresponde a um translinguismo, conforme denominado por Cangi, e se afirma na fusão de elementos linguísticos, sociais e culturais na composição de um relato híbrido. Esse hibridismo, por sua vez, constitui-se na antropofagia, no constante devorar de culturas em busca da assimilação de seus elementos a fim de fundar o novo, o devenir.

Por conseguinte, em Mar paraguayo (1992), a linguagem é vertiginosa e aponta para os extremos do experimentalismo linguístico, em um movimento de libertação das gramáticas como estruturas de poder, transcendendo as fronteiras geográficas, espaciais e culturais e questionando a todo momento os conceitos de unidade e pureza impostos pela colonização e descolonização.

\section{Considerações finais}

Conforme anuncia o Prefácio, escrito por Néstor Perlongher, a publicação de Mar paraguayo (1992) se constitui como um "acontecimento" que "[...] passa pela invenção de uma língua" (PERLONGHER, 1992, p. 7).

Nessa perspectiva, a estruturação do romance, nos limiares entre a poesia e a prosa, nas fronteiras entre as línguas, as gramáticas e as culturas, utilizando o guarani como ponto de

6Tradução Nossa: O entre-lugar não se afirma por zonas semânticas estáveis, substantivos ou verbos, mas por expressões preposicionais que afirmam a tendência elásticas dos sólidos [...]. Define o umbral do entrelugar em toda a sua existência paradoxal como um dentrofora e como um trânsito. Espaço onde a intensidade produz uma vertigem entre línguas, com a força de uma paisagem própria e costumes ancestrais que se fundem em um translinguismo migrante. 


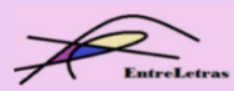

REVISTA ENTRELETRAS (ARAGUAÍNA), V. 12, N. 3, SET./DEZ. 2021 (ISSN 2179-3948 - ONLINE)

destaque, fazem com que estabeleça um diálogo com outros textos que se propõem a romper com a opressão colonialista e neocolonialista. Em plena década de 1990, ao colocar a língua indígena como destaque, Mar paraguayo (1992) se insere em um projeto literário iniciado no Romantismo e que tem no Modernismo seu ápice, na ruptura com a tradição e no enfrentamento às amarras do colonialismo.

O uso do guarani, ao lado do experimentalismo linguístico na mescla entre português e espanhol constituem o hibridismo no relato da marafona e são utilizados como instrumentos para questionar a unidade apregoada pelo colonialismo e também a pureza, que são os pilares de sustentação do domínio do conquistador e, posteriormente, do neocolonialismo e seu apelo ao consumismo.

Por fim, o relato híbrido aponta para a valorização do elemento indígena, deslocando as línguas hegemônicas e destacando a língua ameríndia em um claro movimento em direção à expressão que se liberta das estruturas discursivas do poder, e também rumo à resistência e à descolonização. A linguagem vertiginosa da marafona se constitui em uma busca pela libertação das gramáticas e pela ruptura de fronteiras geográficas, linguísticas, socais e culturais.

\section{Referências}

BUENO, W. Mar paraguayo. São Paulo: Iluminuras, 1992.

BUENO, W. Uma conversa com Wilson Bueno. Suplemento Literário do Minas Gerais, 2000b. Disponível em: http://www.cronopios.com.br/site/artigos.asp?id=4594. Acesso em 12 jan. 2021. Entrevista concedida a Cláudio Daniel.

CANGI, A. Imprevistos de la vida, torsiones del lenguage. In: BUENO, W. Mar Paraguayo. Buenos Aires: tsé-tsé, 2005.

FLORENTINO, N. N. L. A vertigem da linguagem em Mar paraguayo, de Wilson Bueno. 2011, 123 f. Dissertação (Mestrado em Letras) - Universidade Federal de Mato Grosso do Sul/Câmpus de Três Lagoas.

FLORENTINO, N. N. L. Entre gêneros e fronteiras: uma leitura de Mar paraguayo, de Wilson Bueno. 2016. Tese (Doutorado em Letras) - Universidade Estadual Paulista "Júlio de Mesquita Filho", Faculdade de Ciências e Letras de Assis, Assis, 2016.

FLORENTINO, N. N. L. ESTEVES, A. R. Wilson Bueno e o (trans)gênero: uma leitura de Mar paraguayo e Jardim Zoológico. Itinerários, Araraquara, n. 48, p. 219-234, jan./jun. 2019.

GONZALEZ, N. Geografia del Paraguay. Asunción: Cuadernos Republicanos, 1993. 


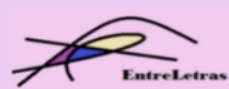

REVISTA ENTRELETRAS (ARAGUAÍNA), V. 12, N. 3, SET./DEZ. 2021 (ISSN 2179-3948 - ONLINE)

GUASH, A; ORTIZ, D. Diccionaraio castellano - Guaraní/ Guaraní - Castellano. Asunción: CEPAG, 1996.

MIGNOLO, W. Bilinguajando o amor: pensando entre línguas. In: MIGNOLO, W. Histórias locais / projetos globais: colonialidade, saberes subalternos e pensamento liminar. Belo Horizonte: UFMG, 2003.

PERLONGHER, N. Sopa paraguaia. In: BUENO, W. Mar paraguayo. São Paulo: Iluminuras, 1992

PLA, J. Español y Guaraní en la intimidad de la cultura paraguaya. In: Cahiers du monde hispanique et luso-brésilien, $\mathrm{n}^{\circ} 14,1970 . \quad \mathrm{pp}$. 7-21.Disponível em http://www.persee.fr/doc/carav_0008-0152_1970_num_14_1_1750. Acesso em 12 jan. 2021.

SANTIAGO, S. O entre-lugar no discurso latinoamericano. In: SANTIAGO, S. Uma Literatura nos Trópicos. 2 ed. Rio de Janeiro: Rocco, 2000. 